\title{
The design of a rotary-wing unmanned aerial vehicles-payload drop mechanism for fire-fighting services using fire-extinguishing balls
}

\author{
Ali Magdi Sayed Soliman ${ }^{1} \cdot$ Suleyman Cinar Cagan ${ }^{1} \cdot$ Berat Baris Buldum ${ }^{1}$
}

(c) Springer Nature Switzerland AG 2019

\begin{abstract}
This study aims to encourage the idea of utilizing unmanned aerial vehicles in the fire-fighting application. In this paper, we present a remote-controlled rotary-wing unmanned aerial vehicle made from metal alloys. This unmanned aerial vehicle, using a payload drop mechanism, can carry fire-extinguishing balls and release them to combat fires, especially in places not easily accessible by humans. The payload drop mechanism is a novel design that has an advantage of dropping two (maximum four) fire-extinguishing balls one at a time using one servo motor. Hence, the servo motor is controlled by one radio channel of the remote controller. Besides, comparing it to our (mechanism A) first designed mechanism, this payload drop mechanism shows smaller horizontal area for fitting most of the drones as well as less effect of vibrations during flight. The whole system is designed using Solidworks platform and manufactured with computer numerical control machining and three-dimensional printing. Thus, the potential use of unmanned aerial vehicles to carry out fire-fighting operations using the proposed payload drop mechanism is successfully examined.
\end{abstract}

Keywords Unmanned aerial vehicle (UAV) · Payload drop mechanism · Fire-extinguishing ball · Wildfires · Servomotor · Three-dimensional printing

\section{Introduction}

Recently, there has been a consistent and developing advancement of unmanned aerial vehicles (UAVs) since their first use in military services such as surveillance, search, and inspection [1]. Currently, the use of UAVs has expanded to civil services such as photography, video filming, and perhaps delivery in the coming future. Hence, this paper re-introduces the idea of using UAVs in extinguishing fires [2], which is a necessary application of UAVs. Firefighting is a critical area that requires physical efforts. It is a well-known fact that every time an accident happens, firefighters are at high risk of being exposed to high rates of toxic smoke and high temperatures [3]. Thus, paying attention to the safety of humans in these industries is a perfect idea aiming at encouraging firefighters to do their job remotely by using UAVs, hence, staying out of danger.
The main advantage of UAVs is their ability to work at rugged places and dangerous environments $[4,5]$. When fire arises in a rugged region, it becomes very challenging for firefighters to combat the fire in a quickest possible manner. Alternatively, UAVs can reach the targeted fire spot and release fire-extinguishing balls before going back to the starting point. Thus, making this type of fire-fighting application much safer than the usual way.

According to Gen. Norton Schwarz [6], "Drones mischaracterize what these things are. They are not dumb. Nor are they unmanned, actually they are remotely piloted aircraft." Drones are either remotely controlled by RC or autonomous pre-programmed. In this paper, we examine the proposed system for the fire-fighting application by following the simple way of building a remote-controlled UAV. UAV, with its integrated camera using a gimbal, is easier to use and also can give the pilot an efficient live

Suleyman Cinar Cagan, cinarcagan@mersin.edu.tr; Ali Magdi Sayed Soliman, ali.magdi.sarhan@gmail.com; Berat Baris Buldum, barisbuldum@mersin.edu.tr | ${ }^{1}$ Mechanical Engineering Department, Engineering Faculty, Mersin University, Mersin, Turkey. 
view. Depending on the aerodynamic flight principle, UAVs can be categorized into fixed-wing and rotary-wing vehicles [7]. Unlike fixed-wing vehicles, rotary-wing vehicles typically have a feature of flying slowly or hovering, taking off or landing vertically [8]. For doing a task of dropping fire-extinguishing balls, rotary-wing UAVs are the proper vehicles to be used. Hence, in this paper, we present a rotary-wing UAV of the quadcopter type.

Fire occurs when three things are present at the same time in the same place; oxygen, fuel, and heat. To extinguish fire, at least one of these three things must be dismissed. In the market, there are many types of cylindershaped fire extinguishers such as water extinguisher, carbon dioxide extinguisher, dry chemical extinguisher, and wet chemical extinguisher. Unfortunately, these fire extinguishers are not suitable for this particular study as they are huge in volume and not self-activating. The other option is a fire-extinguisher ball called Elide Fire Ball (EFB). This ball is environment-friendly since it keeps the oxygen levels intact when it is activated; hence, increases the safety of humans whenever they are near the fire extinguisher (EFB) [9]. Conversely, its disadvantage is that it has relatively a big diameter of 0.145 meters and a heavy weight of 1.5 kilograms [9]. Recently, Tafila Technical University (TTU) made fire extinguishing balls (Fig. 1) resembling the EFB but in a smaller diameter around $8 \mathrm{~cm}$ and a weight of $200 \mathrm{~g}$ [5]. The fire extinguishing balls are comprised of three components: plastic casting composed of a mixture (Gypsum and rubber-based bonding agent (CF 200)), firefighting agent (Monoammonium Phosphate), and a pyrotechnic detonator [5]. The proposed payload drop mechanism is based on this type of fire extinguishing balls.

For releasing one fire-extinguishing ball from a UAV, we may design a payload drop mechanism that carries solely one ball. Dropping this ball is achieved by using one servo motor that takes its signal from the $\mathrm{RC}$, rotates by particular degrees to actuate the mechanism's elements, thereby

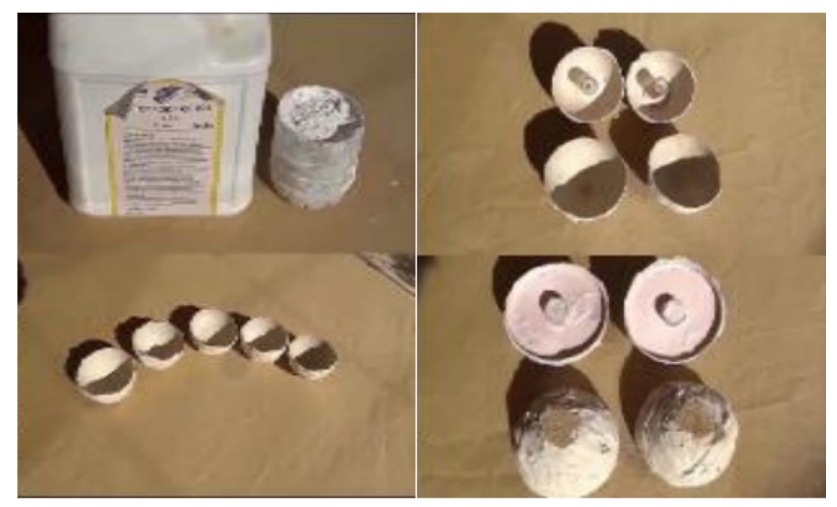

Fig. 1 Fire extinguishing balls (image source: [5]) driving the ball to fall according to the mechanism design. However, in case that many balls have to be dropped from the UAV one at a time, the same number of servo motors equivalent to the number of these balls will be required. Moreover, the same number of radio channels are required as the number of servo motors; therefore, making the system's cost so high. Thus, to avoid building a high-priced system, the designed novel mechanism can release two or maybe four fire-extinguishing balls one at a time using just one single servo motor controlled by a remote controller (RC) of one radio channel [10]. Inside this new mechanism, the balls move vertically; hence, the mechanism has a small horizontal area approximately equal to the projected area of one ball. Additionally, in comparison to our first designed mechanism in which the balls move in a horizontal plane, this one shows less effect of vibrations and much calmness during the flight.

\section{Method}

To fulfill the objective of the paper and confirm the potential use of UAVs for fire-fighting services, the two key elements, UAV and payload drop mechanism, are followed. In this section, the structure is as follows: Firstly, we take a glance at building a quadcopter model. Secondly, we present in detail the UAV- payload drop mechanism. The general design procedure of the payload drop system, design requirements, CAD modeling, working principle, servomotor selection, fabrication method, and experiment are followed.

\subsection{UAV}

Generally speaking, UAVs can fly almost anywhere; over high buildings, mountains, and forests. A supplementary system installed on the UAV can make the UAV serve for a separate application. UAV is the first main factor of this project. During the design process of the UAV, we went through many phases as depicted in Fig. 2 [11]; starting from the conceptual design, passing by learning safety issues, soldering, and flying, and ending with the testing and final design report.

\subsubsection{UAV frame}

UAV frame is the first fundamental element of the UAV; it serves like the skeleton of the human body and it is the most influenced by mechanical stresses [12]. It supports all the UAV's other elements such as motors, propellers, ESCs, flight controller system, and battery. Among many types of UAV frames such as tricopter, quadcopter, hexacopter, and octocopter, quadcopter frame is the chosen. 
Fig. 2 UAV general design procedure [9]

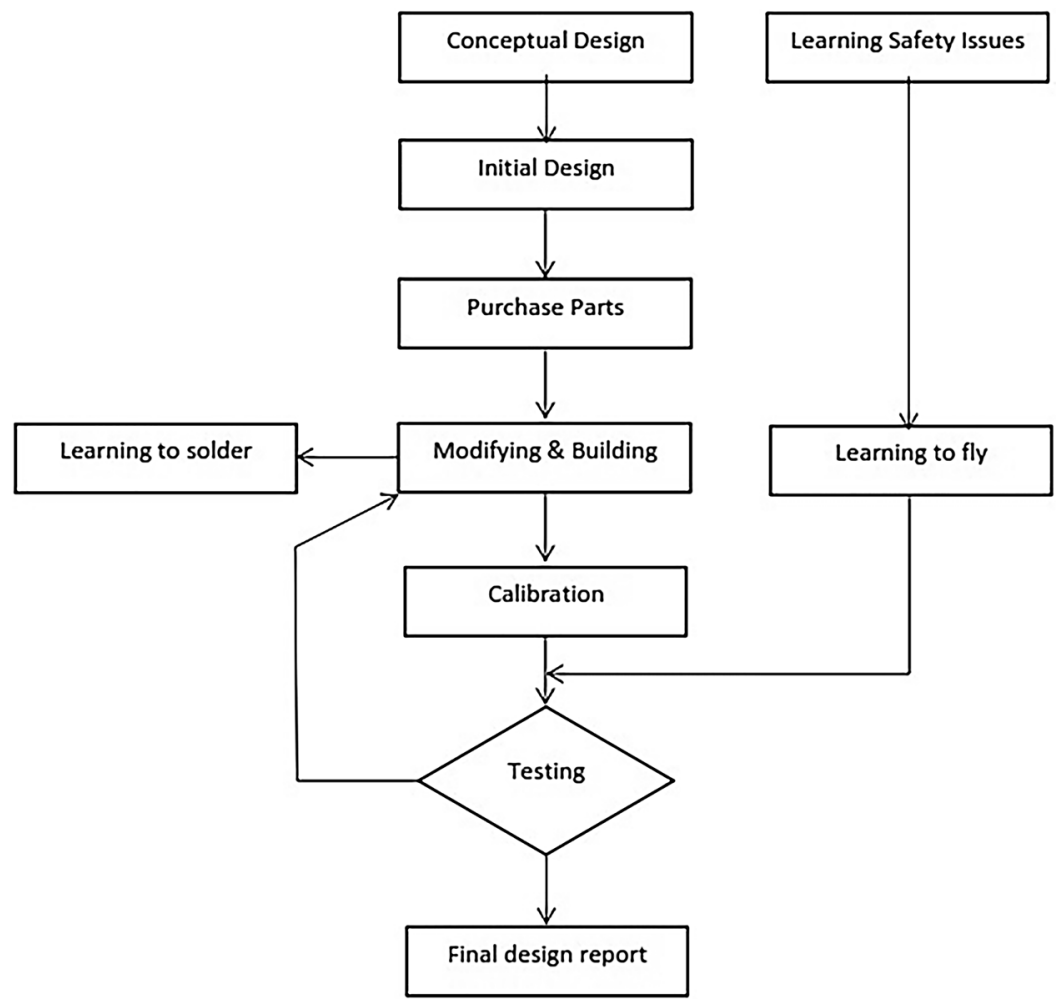

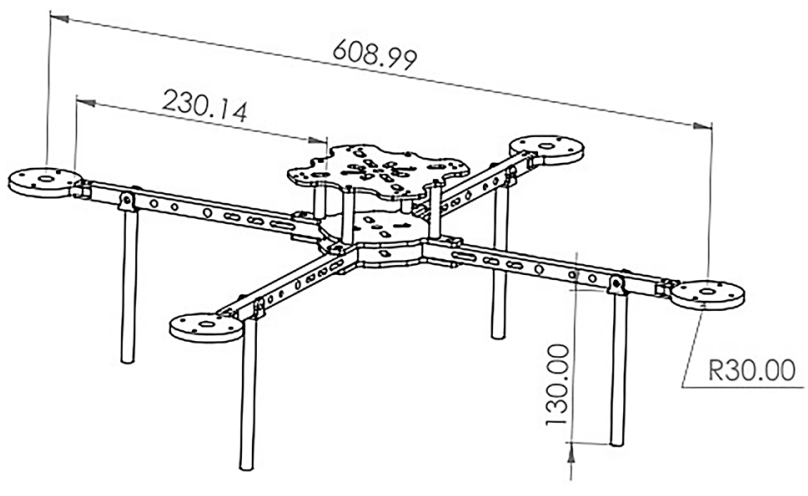

Fig. 3 CAD model assembly of the quadcopter frame

The quadcopter is the most used UAV frame because it has a pretty simple structure. It consists of four rotors fixed at the end of the frame structure. Pair of rotors rotate clockwise, and the other pair rotate counterclockwise [13]. Each rotor is connected to a propeller that creates the thrust force. According to this overall picture, our frame has been designed in Solidworks platform (Fig. 3). This frame consists of four booms, four mounts of the motors, four legs, three central hubs, and four supports for the top central hub. Depending on the needed quality of the aircraft, UAV frame can be made from materials such as plastic, wood, metal, carbon fiber, and metal alloy. From among these materials, we decided to make the frame from a metal alloy to acquire a low price, high solidity, and long-term durability for the frame.

Magnesium and its alloys have unusual properties such as low density $\left(\rho_{m g}=1.74 \mathrm{~kg} / \mathrm{cm}^{3}\right)$, good strength/weight ratio, high heat dissipation, and high damping capacity [14-17]; therefore, they are the candidate materials that compete powerfully with the other various engineering materials used in aerospace and automotive industries. However, because of their high sensitivity to galvanic and pitty corrosions, their utilization is still restricted [15]. One of the most widely used magnesium alloys is AZ91D. From the naming convention, it contains $9 \%$ of aluminum, $0.2 \%$ of zinc, and $0.2 \%$ of manganese [16]. The aluminum inside the alloy makes a rise in the hardness and tensile strength of the alloy [17]. In Table 1, the material comparison of the most candidate materials; magnesium alloy, aluminum alloy, and carbon fiber are given.

Using CNC machining, all the frame parts have been manufactured from AZ91D except for the sheet metals (motor mounts and central hubs) and the top central hub supports that for the ease of manufacturing, have been fabricated from an aluminum alloy (20240). The total mass of the frame, after fabrication, is around $800 \mathrm{~g}$.

Quadcopter frame is easily influenced by the external loads applied to it and tends to be unstable. To increase the stability of the quadcopter, we may put inclined plastic supports (Fig. 4), made by 3D printing, under each motor. These supports tilt the plane of rotations of every 
Table 1 Physical and mechanical properties of magnesium alloy, aluminum alloy, and carbon fiber [16, 18]

\begin{tabular}{|c|c|c|c|}
\hline Properties & $\begin{array}{l}\text { Magnesium Alloy } \\
\text { (AZ91D) }\end{array}$ & Aluminium alloy (2024) & Carbon fiber \\
\hline $\begin{array}{l}\text { Density at room temperature } \\
\left(\mathrm{g} / \mathrm{cm}^{3}\right)\end{array}$ & 1.81 & 2.77 & $\begin{array}{l}\text { Standard: } 1.78 \\
\text { Intermediate: } 1.78 \\
\text { High: } 1.81 \\
\text { Ultrahigh: } 2.12-2.19\end{array}$ \\
\hline Elastic modulus (Gpa) & 45 & 72.4 & $\begin{array}{l}\text { Standard: } 230 \\
\text { Intermediate: } 285 \\
\text { High: } 400 \\
\text { Ultrahigh: } 520-940\end{array}$ \\
\hline Tensile strength (Mpa) & $\begin{array}{l}\text { As cast } \\
165-230\end{array}$ & $\begin{array}{l}\text { Annealed (O temper): } 185 \\
\text { Heat-treated and aged (T3 temper): } 485 \\
\text { Heat-treated and aged (T351 temper): } 470\end{array}$ & $\begin{array}{l}\text { Standard: } 3800-4200 \\
\text { Intermediate: } 4650-6350 \\
\text { High: } 2500-4500 \\
\text { Ultrahigh: } 2620-3630\end{array}$ \\
\hline Cost (\$US/kg) & 3.40 & $\begin{array}{l}\text { Sheet, T3 temper: } 12.50-19.50 \\
\text { Bar, T351 temper: } 11.00-21.00\end{array}$ & $\begin{array}{l}\text { Standard: } 40.00-80.00 \\
\text { Intermediate: } 60.00-130.00 \\
\text { High: } 220.00-275.00 \\
\text { Ultrahigh: } 1750-2650\end{array}$ \\
\hline
\end{tabular}

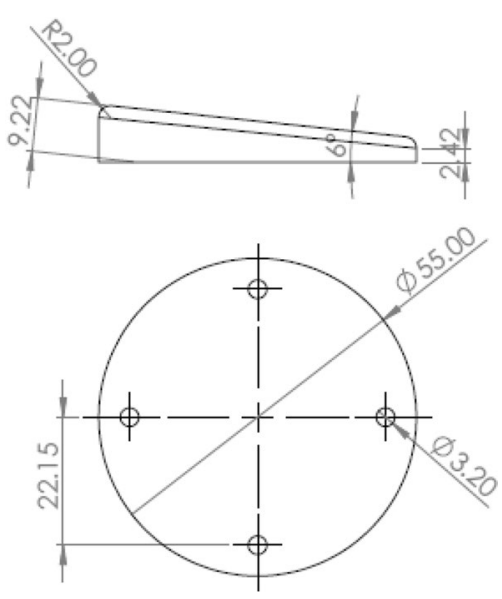

Fig. 4 Plastic support yielding a dihedral angle of $6^{\circ}$

rotor inwards and hence increase the intrinsic stability of the quadcopter during a hover [19]. Small dihedral angle $\left(6^{\circ}\right)$ is used; therefore, the reduced energetic efficiency of the UAV is not significant [19].

\subsubsection{UAV electronic components}

Table 2 shows the essential electronic components used to build the quadcopter. The appointed receiver has an operating range of more than $1.5 \mathrm{~km}$; therefore, the pilot can be quite far from the fire and remain safe. In Fig. 5a, $b$, the quadcopter assembly, and the quadcopter while flying are shown, respectively. This quadcopter takes approximately $9 \mathrm{~min}$ of mixed flight, which is likely to be enough for carrying out a fire-fighting mission.

\subsection{Payload drop mechanism}

Payload drop mechanism is the second major factor of this project, and the mounting it on the UAV gives the vehicle the desired ability to aid in fire extinguishing operations. Thus, for designing a new mechanism, we followed this track of design process as illustrated in Fig. 6.

The traditional way for dropping an object from a UAV has been using servo-mechanized system (a door-type mechanism) that uses a single servomotor to create rotational motion and drop an object. However, using such a system, especially when the vehicle is airborne, another object is not expected to be released. Therefore, through this way of dropping, a swarm of drones will be needed to drop many fire-extinguishing balls for a firefighting operation; otherwise, the mission will not be carried out. To solve this problem, the novel mechanism should be used to release many fire-extinguishing balls one at a time at various moments using a servomotor controlled by one radio channel. This is because by using only one radio channel we are to facilitate the control of the payload drop system, as well as, reduce the cost of the system since the price of a 16-channels remote controller is not the same as the price of a one-channel remote controller, and we may save that cost difference for other needs. Below is a list of the design requirements of the payload drop system.

- Carry several fire-extinguishing balls ( 2 balls, at least).

- Release balls in a controlled manner one after another.

- Be controlled using a single radio channel of the remote controller.

- Appropriate for, perhaps, most of the different UAVs'sizes. 
Table 2 UAV electronic components

\begin{tabular}{|c|c|}
\hline Component & Attributes \\
\hline Brushless DC Motor & $\begin{array}{l}\text { Name: T Motor MT2814 } \\
\text { Weight: } 120 \mathrm{~g} \\
\text { Total weight (with its cables): } 160 \mathrm{~g} \\
\text { Stator diameter: } 28 \mathrm{~mm} \\
\text { Stator length: } 14 \mathrm{~mm} \\
\text { Shaft diameter: } 4 \mathrm{~mm} \\
\text { KV: } 770 \text { RPM/volt } \\
\text { Battery cells: } 3 \mathrm{~S}, 4 \mathrm{~S} \\
\text { Maximum continuous current (180S): } 29 \mathrm{~A} \\
\text { Maximum continuous power (180S): } 500 \mathrm{~W}\end{array}$ \\
\hline Electronic Speed Controller (ESC) & $\begin{array}{l}\text { Name: DJI Opto } 30 \mathrm{~A} 4 \mathrm{~S} \\
\text { Battery cells: } 4 \mathrm{~S}-6 \mathrm{~S} \\
\text { Maximum current: } 30 \mathrm{~A} \\
\text { Voltage: } 14.8 \\
\text { Weight: } 23 \mathrm{~g} \\
\text { Signal Frequency: } 30-450 \mathrm{~Hz}\end{array}$ \\
\hline Propellers & $\begin{array}{l}\text { Name: APC SF } 12 \times 3.8 \\
\text { Weight: } 10 \mathrm{~g} \\
\text { Number of blades: } 2 \\
\text { Diameter: } 12 \text { inch }=304.8 \mathrm{~mm} \\
\text { Pitch: } 3.8 \text { inch }=96.52 \mathrm{~mm} \\
\text { Shaft diameter: } 1 / 4 \text { inch }=6.35 \mathrm{~mm}\end{array}$ \\
\hline Battery & $\begin{array}{l}\text { Name: Gens ace } 7000 \text { mAh } 14.8 \mathrm{~V} \text { LiPo } \\
\text { Weight: } 605 \mathrm{~g} \\
\text { Capacity: } 7000 \mathrm{mAh} \\
\text { Voltage: } 14.8 \mathrm{~V} \\
\text { Discharge rate: } 50 \mathrm{C} \\
\text { Maximum burst discharge rate: } 100 \mathrm{C} \\
\text { Configuration: } 4 \mathrm{~S} 1 \mathrm{P}\end{array}$ \\
\hline Flight controller system & $\begin{array}{l}\text { Name: DJI Wookong M } \\
\text { Flight controller weight: } 20 \mathrm{~g} \\
\text { IMU weight: } 50 \mathrm{~g} \\
\text { PMU weight: } 30 \mathrm{~g} \\
\text { LED weight: } 15 \mathrm{~g} \\
\text { GPS weight: } 50 \mathrm{~g} \\
\text { Total weight: } 165 \mathrm{~g} \\
\text { Maximum power consumption: } 5 \mathrm{~W} \\
\text { Hovering accuracy (GPS): Vertical: } \pm 0.5 \mathrm{~m} \text {, } \\
\text { Horizontal: } \pm 2 \mathrm{~m} \\
\text { Max. Yaw angular velocity: } 150 \mathrm{deg} / \mathrm{s} \\
\text { Max. tilt angle: } 35^{\circ} \\
\text { Ascent/descent: } \pm 6 \mathrm{~m} / \mathrm{s} \\
\text { Recommended battery: } 2 \mathrm{~S} \text { to } 6 \mathrm{~S} \mathrm{LiPo} \\
\text { Supported ESC: } 400 \mathrm{~Hz} \text { frequency }\end{array}$ \\
\hline Software & DاJ ground station \\
\hline Telemetry radio & $\begin{array}{l}\text { Name: DJI datalink } 2.4 \mathrm{GHz} \\
\text { Weight: } 30 \mathrm{~g}\end{array}$ \\
\hline Receiver & $\begin{array}{l}\text { Name: } X 8 R \text { FrSky } \\
\text { Weight: } 15 \mathrm{~g} \\
\mathrm{~L} \times \mathrm{W} \times \mathrm{H}: 46.25 \times 26.6 \times 14.2 \mathrm{~mm} \\
\text { Operating range: full range }(>1.5 \mathrm{~km}) \\
\text { Operating current: } 100 \mathrm{~mA} \text { at } 5 \mathrm{~V}\end{array}$ \\
\hline Transmitter & $\begin{array}{l}\text { Name: FrSky } 2.4 \text { G ACCST Taranis } \\
\text { Number of channels: } 16\end{array}$ \\
\hline Power distribution board & $\begin{array}{l}\text { Matek fchub-6s } \\
\text { Battery cells: 3S-6S LiPo } \\
\text { Weight: } 9 \mathrm{~g}\end{array}$ \\
\hline
\end{tabular}


- Not to significantly affect the aircraft's COF (center of gravity).

- Use solely one servo motor.

- Be manufactured from light weight material by 3D printing.

Fig. 5 a Assembly of the quadcopter. b Quadcopter during flight

\subsubsection{Mechanism A}

Mechanism A, as shown in Fig. 7, is the first idea that was intended during the design process. It consists of a payload box (Fig. 7a) and a rotor (Fig. 7b). As shown in Fig. 7c, the balls are placed in the empty spaces between the rotor blades. When the servo motor rotates the rotor, the payloads will descend through the hole at the bottom inside the payload box. The advantage of this mechanism

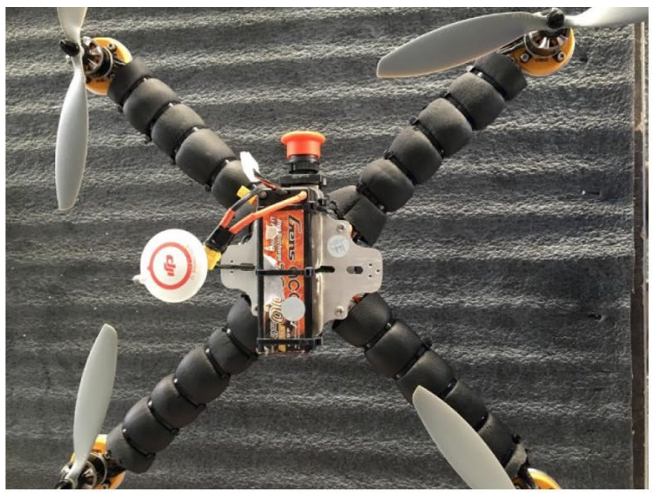

(a)

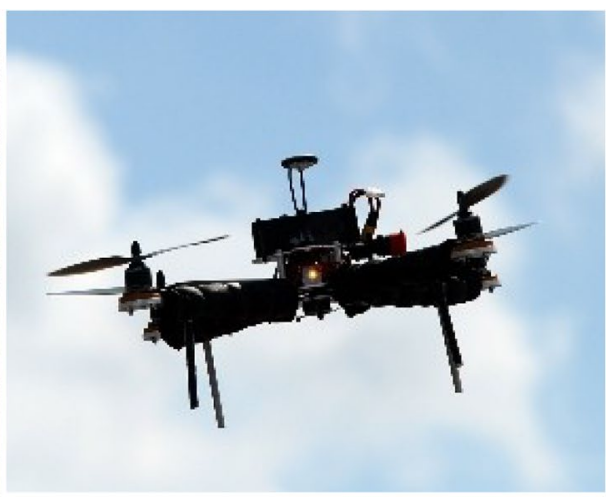

(b)

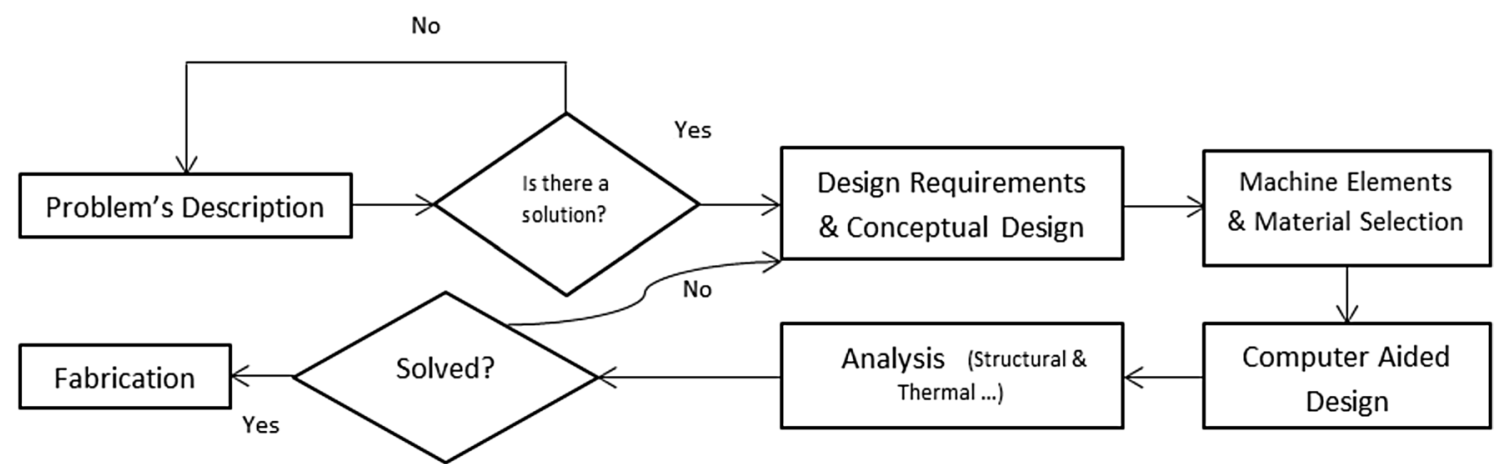

Fig. 6 Design process diagram of the payload drop mechanism

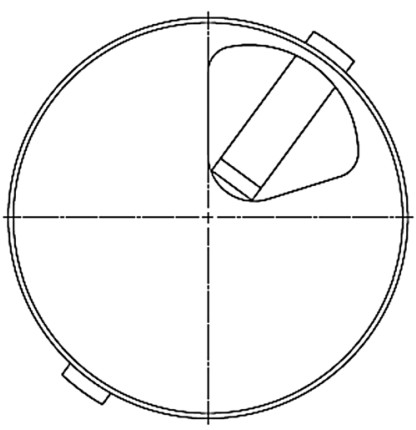

(a)

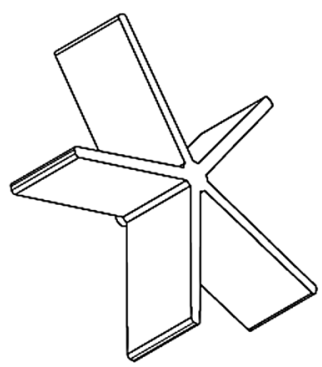

(b)

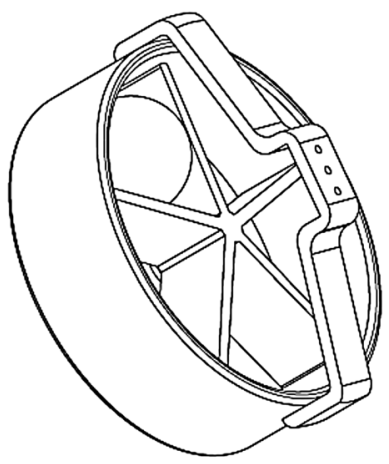

(c)

Fig. 7 a Payload box. b Rotor. c Assembly of payload drop mechanism A 
is that it can release payloads of different diameters and different shapes. However, this cannot be accredited to this mechanism because the payloads inside the mechanism move in a horizontal plane, making the quadcopter vibrate during flight as a result of changes in the center of gravity. Besides, most of the commercial servomotors can rotate less than $360^{\circ}$, thereby making it difficult to get a 360-degree servo motor.

Additionally, the system horizontally occupies a significant volume; therefore, it can not fit smaller drones. In Fig. 8, geometrical analysis has been done to calculate the horizontal projected area of the mechanism and thus compare it with mechanism B. Initially, it is assumed that the mechanism radius $(R)$ is equal to three times the ball radius $(r)$ as in Eq. 1:

$R=3 r$

where $r$ is $40 \mathrm{~mm}$. The full circle in the figure indicates the projected fire-extinguishing ball that its center can exist on the symmetry line $(\mathrm{oD})$ between points $A$ and $B$. Point A can be obtained approximately from Eq. 2:

$A=\frac{68.05}{120} R \cong 0.568 R$

And point B can be obtained from Eq. 3:

$B=\frac{2}{3} R$

For calculating the minimum horizontal radius of the mechanism (oC), the rotor sides (oi and of) are tangent to the ball, the ball center is at point $A$, and point $D$ goes to point $C$. Accordingly, the minimum projected radius of mechanism A can be expressed as in Eq. 4:
$R \cong 0.568(3 r)+r \cong 2.704 r$

Eventually, the minimum horizontal projected area of the mechanism is obtained from Eq. 5:

$A_{\text {horizontal }}=\pi R^{2} \cong(2.704)^{2} \pi r^{2}$

\subsubsection{Mechanism B}

To meet the design requirements stated above and avoid the drawbacks seen in mechanism A, we designed mechanism $B$ (Fig. 9) that is considered as the final design. In mechanism $B$, the minimum horizontal projected area can be obtained approximately from Eq. 6:

$A_{\text {horizontal }}=\pi R^{2} \cong \pi r^{2}$

In comparison to mechanism $A$, mechanism $B$ has less horizontal projected area; therefore, it is more appropriate to fit in smaller drones. Besides, mechanism $B$ is much simpler design as it consists of only two essential components: a payload box (Fig. 8a) and an actuation arm (Fig. 9b). The function of this mechanism is as follows: The balls are placed inside the payload box in chambers on top of each other and, at the end of the cylindrical payload box, an overhang of the actuation arm becomes precisely beneath the lowest ball to prevent the whole balls from descending. When the actuation arm connected to a servo motor rotates nearly $70^{\circ}$, accordingly, all the overhangs on the actuation arm rotate, as well. That is why the last ball at the bottom falls, and at the same time, the separator overhang becomes beneath the first ball to avoid its falling. For falling the remaining ball, a second rotational movement of $70^{\circ}$ occurs once again. The trace path of the overhang's
Fig. 8 Geometrical analysis of the ball inside the rotor

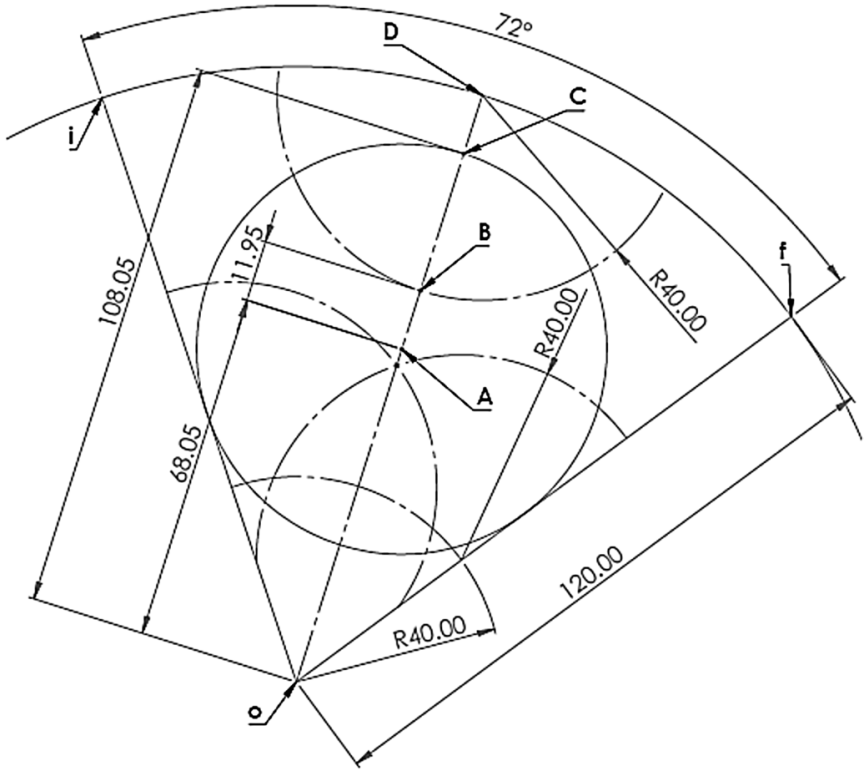


Fig. 9 a Payload box. b Actuation arm. c Assembly of payload drop mechanism $B$

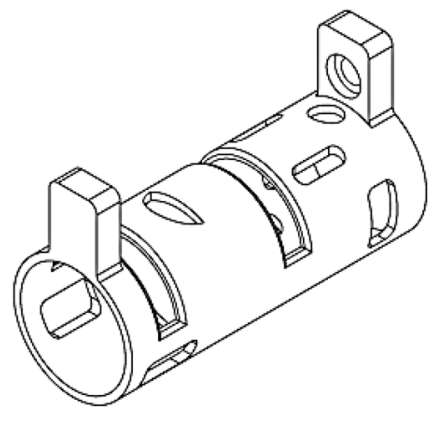

(a)

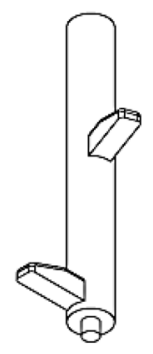

(b)

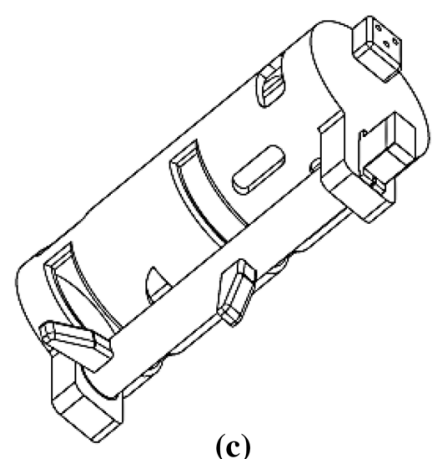

(c)

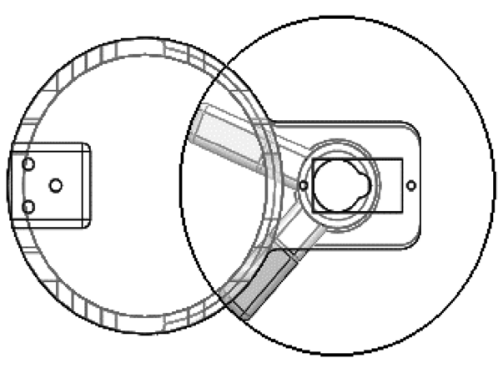

Fig. 10 Trace path of the actuation arm

edge of the actuation arm is shown in Fig. 10. Dropping the maximum number of four balls is in the same manner, but the mechanism should have an actuation arm with four overhangs, a payload box with four chambers, and servomotor that can rotate $280^{\circ}$.

\subsubsection{Servomotor selection}

To choose the appropriate servo motor for the mechanism, torque analysis [20] has been done to calculate the torque necessary to perform the drop. The basic torque analysis is conducted using the torque expression stated in Eq. 7 as:

$\tau=r F_{\text {total }}$

where $r$ is the moment arm and $F_{\text {total }}$ is the total opposing force. There are two kinds of forces that may resist the motion of the actuation arm: force due to the weight of payloads and force due to the friction of the sliding surfaces of the mechanism. The force due to the payloads' weight on the overhangs of the actuation arm is stated in Eq. 8 as:

$F_{\text {weight }}=\mu_{w} N_{w}$

where $\mu_{w}$ is the surface to surface friction constant (between the overhang and the ball) and $N_{w}$ is the weight of one ball. The force due to friction is stated in Eq. 9 as:

$F_{\text {friction }}=\mu_{f} N_{s s}$ where $\mu_{f}$ is the surface to surface friction constant and $N_{s s}$ is the load of sliding surfaces. The total opposing force is the sum of all forces determined above, as stated in Eq. 10:

$F_{\text {total }}=F_{\text {weight }}+F_{\text {friction }}=\mu_{w} N_{w}+\mu_{f} N_{s s}$

By using ball bearings, the friction between the actuation arm and the payload box surfaces can be neglected and hence the term $F_{\text {friction }}$ can be eliminated as stated in Eq. 11:

$F_{\text {total }}=F_{\text {weight }}=\mu_{w} N_{w}$

From Eqs. 1 and 5, the opposing torque can be determined as stated in Eq. 12:

$\tau=r \mu_{w} N_{w}$

The necessary stall torque of the servo motor is given in Eq. 13 as:

$\tau_{\text {servomotor }}>r \mu_{w} N_{w}$

To guarantee good performance, it is recommended to use a servo motor of stall torque given in Eq. 14:

Stall torque $\geq 4 \tau_{\text {servo motor }}$

\subsubsection{Experiment and verification}

This experiment aims to show the prototype of the new mechanism and its potential to achieve the idea of using UAVs in the fire-fighting application. Using 3D printing, the UAV- payload drop mechanism was manufactured from the Polylactic Acid (PLA) filament as a printing material with an infill ratio of $20 \%$ (Fig. 11). The total mass of the mechanism is $215 \mathrm{~g}$.

This is a servomotor actuated-mechanism, according to the Eqs. 7-14, an appropriate servo motor for the mechanism was selected. Any servomotor of stall torque equal to or higher than $1.18 \mathrm{kgf} \mathrm{cm}$ such as TowerPro MG90S servo motor is considered proper, as stated in Eq. 15:

Stall torque $\geq\left(4 r \mu_{w} N_{\text {weight }}=1.18\right) \mathrm{kgf} \mathrm{cm}$

where $r$ is $0.03 \mathrm{~m}, \mu_{w}$ is 0.492 , and $N_{\text {weight }}$ is $200 \mathrm{~g}$. In addition to that, an additional battery and receiver plus an 


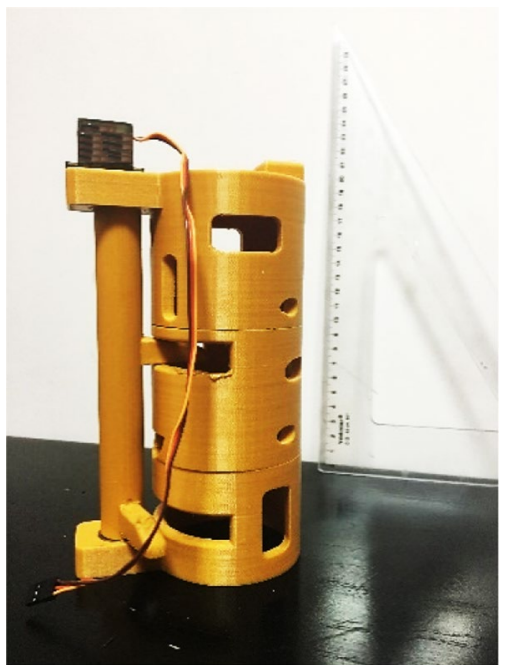

Fig. 11 Payload drop mechanism B fabricated via 3D printing

extra remote controller of one channel was used for controlling the mechanism.

As shown in Fig. 12, we equipped the quadcopter with the payload drop mechanism and checked the new payload drop mechanism using plastic model of balls that resemble the fire-extinguishing balls of Tafila Technical University. Since the balls in the mechanism move vertically inside the payload box, the dropping does not affect the horizontal equilibrium of the quadcopter in comparison to mechanism A. Each time after dropping another pair of balls, the UAV should return for reloading, so that the recommended UAV with two of the upgraded version of this payload drop mechanism can drop the maximum number of four fire-extinguishing balls; therefore, the UAV can drop eight fire-extinguishing balls in one trip. Finally, to ensure safety, if the fire did not stop after dropping the fire-extinguishing balls, the firefighting men should instantly deal and keep up with it using their traditional way of firefighting.

\section{Conclusions and future work}

Using UAVs in firefighting applications can help those whose lives are at risk whenever fire erupts somewhere. Additionally using UAVs, can make firefighting missions get fulfilled much quicker than what it is used to be. In this work, as stated above, we presented a quadcopter vehicle fabricated from metal alloys and equipped with a newly designed payload drop mechanism. This new design of the payload drop system can release four fire extinguishing balls (as a maximum) one at a time with just a single servo motor controlled by one radio channel so that the cost of building such a system is decreased. Secondly, inside the payload drop system, the balls move in a vertical plane; therefore, the system is horizontally small enough to fit small drones and does not generate vibrations to the UAV during the flight as a result of changing the center of gravity. Finally, the payload drop mechanism is so simple as it consists of solely two parts that can be easily fabricated by 3D printing. However, the payload drop mechanism has a disadvantage of not working with various diameters of balls and not roundshaped objects. In future work, we recommend the optimization of the payload drop system so that it can drop objects of different shapes, as well. Furthermore, a gimbal should be integrated into the UAV frame to mount a camera and let the firefighting pilot be much safe and watch the fire through an FPV (First Person View) goggles. In the end, any efforts in the research and development addressing the fire-extinguishing application will lead to compelling systems that could be operated using UAVs soon.
Fig. 12 Snapshots of the payload drop mechanism in use: a Quadcopter in hovering. b Dropping off the ball

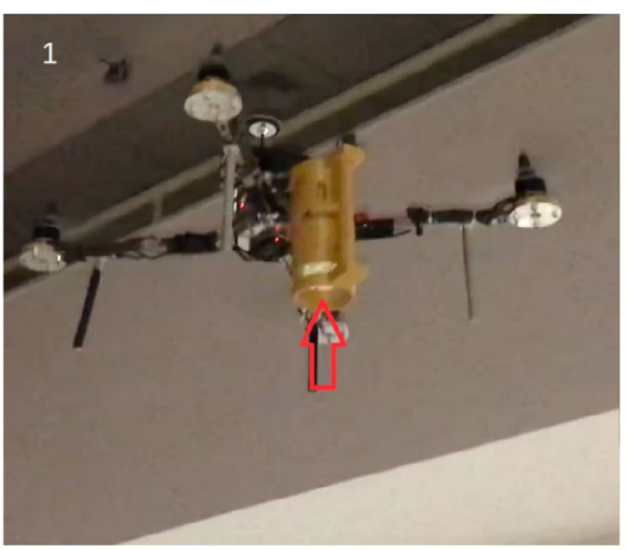

(a)

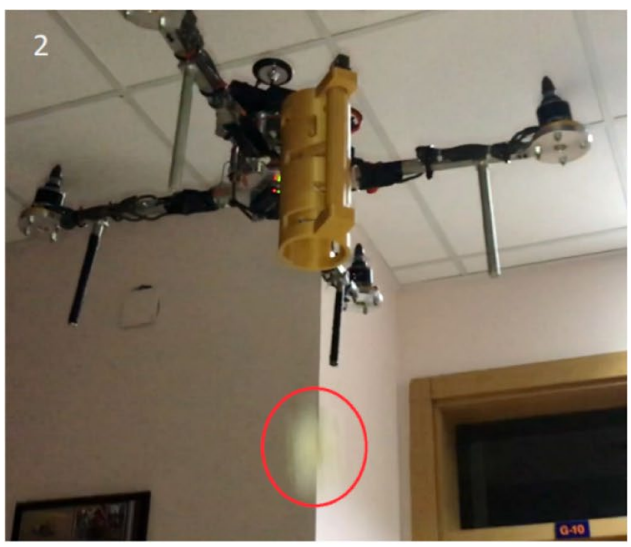

(b)

SN Applied Sciences a SPRINGER NATURE journa 
Acknowledgements This work was also contributed to by the following two undergraduate students at Mersin University:Tofig Bannayev and Ezel Lezgin Adiguzel. We would like to thank the fabrication of the UAV's frame and Mersin Genc Girisimci Merkezi for their help with the fabrication of the payload drop mechanism.

Funding This research was funded by Turkiye Bilimsel ve Teknolojik Arastirma Kurumu (Tubitak), Grant Number 40318666-7197.

\section{Compliance with ethical standards}

Conflict of interest The authors declare no conflict of interest.

\section{References}

1. Valavanis KP (2008) Advances in unmanned aerial vehicles: state of the art and the road to autonomy. Springer, Berlin. https:// doi.org/10.1007/978-1-4020-6114-1

2. Ollero A, Martínez-de-Dios JR, Merino L (2006) Unmanned aerial vehicles as tools for forest-fire fighting. For Ecol Manag 234:S263. https://doi.org/10.1016/j.foreco.2006.08.292

3. Dirisu JO, Fayomi OSI, Oyedepo SO, Mmuokebe JI (2019) Performance assessment of the firefighting personal protective tunic. Energy Procedia 157:405-418. https://doi.org/10.1016/j.egypr o.2018.11.205

4. Klippstein $H$, Hassanin $H$, De Cerio Diaz, Sanchez A, Zweiri Y, Seneviratne $L$ (2018) Additive manufacturing of porous structures for unmanned aerial vehicles applications. Adv Eng Mater 20(9):1-10. https://doi.org/10.1002/adem.201800290

5. Alshbatat AIN (2018) Fire extinguishing system for high-rise buildings and rugged mountainous terrains utilizing quadrotor unmanned aerial vehicle. Int J Image Graph Signal Process 10(1):23-29. https://doi.org/10.5815/ijigsp.2018.01.03

6. Kumar V (2019) Robotics: aerial robotics. In: Coursera. https:// www.coursera.org/learn/robotics-flight/lecture/V136S/unman ned-aerial-vehicles. Accessed 14 Feb 2019

7. González-Jorge H, Martínez-Sánchez J, Bueno M, Arias P (2017) Unmanned aerial systems for civil applications: a review. Drones 1(1):2. https://doi.org/10.3390/drones 1010002

8. Qi J, Kang J, Lu X (2018) Design and research of UAV autonomous grasping system. In: 2017 IEEE international conference on unmanned systems, ICUS 2017, 2018, pp 126-131. https:// doi.org/10.1109/ICUS.2017.8278328

9. Beltran C (2013) Unmanned aerial vehicle with fire extinguishing grenade release and inspection system: $100 \%$ report.
Dissertation, Florida International University. https://mme.fiu. edu/wp-content/uploads/2013/12/F13-SR-T-4.pdf

10. Gupta G (2014) Controlled multiple-object-dropping mechanism using single radio channel in UAVs. IOSR J Mech Civ Eng 11(5):102-109. https://doi.org/10.9790/1684-1151102109

11. Bryceson K, Borrero AN, Camilleri C, Vasuian F (2016) Small quadcopter drones as educational tools in agriculture at the University of Queensland. In: 8th international conference on education and new learning technologies (EDULEARN), Barcelona, Spain. https://doi.org/10.21125/edulearn.2016.0767

12. Martinetti A, Margaryan M, Dongen LV (2018) Simulating mechanical stress on a micro Unmanned Aerial Vehicle (UAV) body frame for selecting maintenance actions. Procedia Manuf 16:61-66. https://doi.org/10.1016/j.promfg.2018.10.160

13. Javir AV, Pawar K, Dhudum S, Patale N, Patil S (2015) Design, analysis and fabrication of quadcopter. J Int Assoc Adv Technol Sci 16(11):1-12

14. Sahu G, Patel PB (2015) A brief review on mg alloys their properties and application. Int J Adv Res Sci Eng 8354(4):65-71

15. Mashtalyar DV, Gnedenkov SV, Sinebryukhov SL, Imshinetskiy IM, Puz AV (2017) Plasma electrolytic oxidation of the magnesium alloy MA8 in electrolytes containing TiN nanoparticles. J Mater Sci Tech 33(5):461-468

16. Buldum BB, Sik A, Ozkul I (2013) Investigation of magnesium alloys machinability. Int J Electron Mech Mechatron Eng 2(3):261-268

17. Fleming $S$ (2012) An overview of magnesium based alloys for aerospace and automotive applications, pp 1-36. https://doi. org/10.1172/JCl66327

18. Callister WD, Rethwisch DG (2012) Materials science and engineering: an introduction, 9th edn. Wiley, New York

19. Efraim H, Shapiro A, Weiss G (2015) Quadrotor with a dihedral angle: on the effects of tilting the rotors inwards. J Intell Robot Syst Theory Appl 80(2):313-324. https://doi.org/10.1007/s1084 6-015-0176-4

20. Iqbal U, Sadiq MS, Shah SIA (2016) Design, development and fabrication of airdrop mechanism for first aid kit drop in unmanned disaster relief helicopter. In: Proceedings of 3rd international conference on engineering and emerging technologies (ICEET), pp 7-8

Publisher's Note Springer Nature remains neutral with regard to jurisdictional claims in published maps and institutional affiliations. 